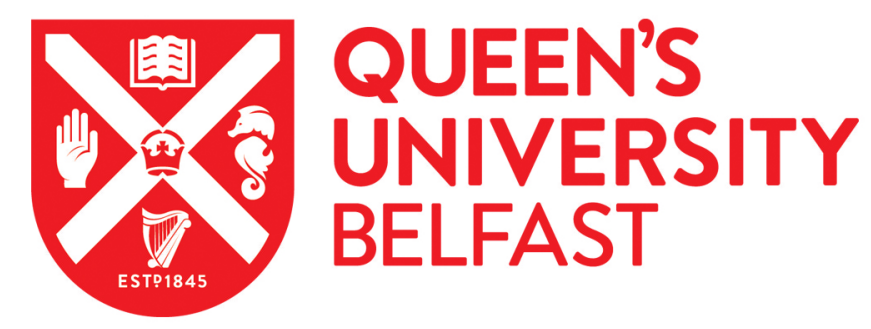

\title{
The development and validation of a toolkit to measure consumer trust in food
}

Benson, T., Lavelle, F., Spence, M., Elliott, C. T., \& Dean, M. (2020). The development and validation of a toolkit to measure consumer trust in food. Food Control, 110, [106988]. https://doi.org/10.1016/j.foodcont.2019.106988

\author{
Published in: \\ Food Control
}

Document Version:

Peer reviewed version

Queen's University Belfast - Research Portal:

Link to publication record in Queen's University Belfast Research Portal

Publisher rights

(C) 2019 Elsevier Ltd.

This manuscript version is made available under the CC-BY-NC-ND 4.0 license http://creativecommons.org/licenses/by-nc-nd/4.0/,which permits distribution and reproduction for non-commercial purposes, provided the author and source are cited.

\section{General rights}

Copyright for the publications made accessible via the Queen's University Belfast Research Portal is retained by the author(s) and / or other copyright owners and it is a condition of accessing these publications that users recognise and abide by the legal requirements associated with these rights.

Take down policy

The Research Portal is Queen's institutional repository that provides access to Queen's research output. Every effort has been made to ensure that content in the Research Portal does not infringe any person's rights, or applicable UK laws. If you discover content in the Research Portal that you believe breaches copyright or violates any law, please contact openaccess@qub.ac.uk. 

Institute for Global Food Security, School of Biological Sciences, Queen's University Belfast, Belfast BT9 5AG, UK. t.benson@qub.ac.uk, flavelle01@qub.ac.uk, m.s.spence@qub.ac.uk, chris.elliott@qub.ac.uk, moira.dean@qub.ac.uk Correspondence: moira.dean@qub.ac.uk, Tel: +442890 976561

Abstract: Consumer trust is an important aspect in the functioning of any market but particularly the food and drinks sector. Food safety incidents and changes in food production practices have simultaneously led to a decrease in consumer trust and a need for greater trust. Previous research has developed items to measure consumer trust in food, however, these have not always been subject to validity and reliability testing and there exists no collated toolkit or collection of items to measure trust in various aspects of the food system. Therefore, the current set of studies aimed to develop a valid and reliable consumer trust toolkit which can be used to measure trust in specific aspects of the food system. Study 1 consisted of a literature review of previous consumer trust measures to construct an initial toolkit of items, followed by an exploratory factor analysis $(n=481)$ to identify the structure of the toolkit. Study $2(n=1,027)$ used confirmatory factor analysis to verify the factor structure of the model from study 1 with six different factors (types of trust): Organisation trust, product trust, interpersonal trust, trust in the food chain, organisation distrust, and general distrust. Study 2 also established the validity of the toolkit (face validity, convergent validity, and discriminant validity). Study 3 resampled a collection of individuals from study 2 ( $n=247)$ to establish composite reliability and temporal stability (test-retest reliability). The resultant consumer trust toolkit provides a valid and reliable collection of items which can be used in future research to measure consumer trust in selected aspects of the food system.

Keywords: Consumer, trust, food, measure, validity, reliability 
Consumer trust is a vital component in any market, without which the selling and purchasing of goods and services as well as the development of new products would prove difficult or impossible (Nuttavuthisit \& Thøgersen, 2017). The concept of trust is broad and overlaps multiple disciplines including economics, psychology, and sociology. Such wide scope has led to the creation of various definitions of trust. For example, it has been defined as the "willingness to rely on an exchange partner in whom one has confidence" (Moorman, Deshpande, \& Zaltman, 1993, p. 82) and "confidence in an exchange partner's reliability and integrity (Morgan \& Hunt, 1994, p. 23) (for further definitions of trust see Bozic (2017)). Arguably the most well-known definition refers to trust as "the willingness of a party to be vulnerable to the actions of another party based on the expectation that the other will perform a particular action important to the trustor, irrespective of the ability to monitor or control that other party" (Mayer, Davis, \& Schoorman, 1995, p. 712). With regards to the consumer, this means that they will spend based upon the expectation that the product or service that they will receive is authentic and genuine. Extensive research has identified several components of consumer trust. At a basic level, expertise and trustworthiness have been highlighted as key factors (Frewer \& Miles, 2003). However, further components are more consistently found in the literature. Specifically, competence, benevolence, integrity, openness, and honesty are some of the components that have been suggested to form trust (For further details see Connolly \& Bannister (2007)).

While consumer trust is essential to any market, it is particularly relevant to the food market. Consumers expect foods available for purchase to be safe and of satisfactory quality. If a consumer trusts and therefore unknowingly purchases and consumes an inauthentic or unsafe product, this may lead to consequences ranging from a poor sensory experience through to illness or death. More than ever, consumers want to know the source of their food and how it was grown, handled, shipped, produced, and packaged, with traceability and transparency key trends (Lu, Wu, Wang, \& Xu, 2016). Some of this desire for information has been a consequence of various well-documented food scandals, for example, the Bovine Spongiform Encephalopathy outbreak in the 1990s and the "horsemeat scandal' in 2013 where beef was substituted with horse meat in a number of products. Such incidents have eroded consumer trust in food (Coveney et al., 2015; Zachmann \& Østby, 2011) and decreased sales in affected products (MacLeod, 2013; Miran \& Akgüngör, 2005; Roosen, Lusk, \& Fox, 2003; Schlenker \& Villas-Boas, 2009). In addition to consumer trust being impacted by food safety incidents, trust can also influence the success of particular brands or products in the food sector. Bruschi and colleagues (2015) found that trust in EU food certification schemes may explain the success of foreign products in particular markets. 
Trust at a wider level is also important in the food sector. Mutual trust between businesses is necessary for food supply chains to operate and be successful (Meixner et al., 2009). Business to business trust is essential given that those in businesses face the same issues as consumers, such as the inability to scrutinize all quality characteristics of food (Fritz, Martino, \& Surci, 2008).

Current consumer trust in the food chain and production system is relatively low (Coveney et al., 2015). In addition to the impact of food scares and safety incidents, it has been suggested that the complexity of the food industry may also affect trust (Giampietri, Verneau, Del Giudice, Carfora, \& Finco, 2018). Increasing sophistication and globalisation of the food market means that consumers are more distanced from the source than ever. This is both literally in terms of urban living and physical proximity to farms and metaphorically with regards to position amongst multiple actors in the food production chain (Berg, 2004; Wilson et al., 2016). This increase in complexity and distance may not only have contributed to a decline in trust but has also simultaneously meant that trust is more important for the consumer than ever. Food safety and quality have been deemed as a 'black box' for consumers who must rely upon and place their trust in the actors involved in various stages of the food chain (De Jonge, Van Trijp, Jan Renes, \& Frewer, 2007; Giampietri et al., 2018).

Transforming consumer trust in food is a current key challenge (Giampietri et al., 2018; PriceWaterhouseCoopers, 2015). Given predicted global trends such as a rapidly increasing population and climate change and the ensuing scarcity of resources, current consumer trust must be rebuilt to ensure a future sustainable food system. Recently the most optimal strategies for rebuilding consumer trust in food were identified by actors in the food system as; transparency, protocols and procedure, be proactive, collaborate with stakeholders, and put consumers first (Wilson et al., 2016). These strategies were also endorsed by consumers (Tonkin et al., 2019). Communication following a food safety incident should demonstrate care, commitment, consistency, coherence, and clarity (Hobbs, 2011).

Traceability and transparency are promising potential solutions to increase consumer trust. For example, Japan has a mandatory beef traceability system allowing consumers to trace beef through their mobile phone or a website using an identification number (Jin \& Zhou, 2014). Other studies have examined the use of traceability in relation to consumer trust in food (Liu, Gao, Nayga Jr, Snell, \& Ma, 2019; Menozzi, Halawany-Darson, Mora, \& Giraud, 2015; Wu, Wang, Zhu, Hu, \& Wang, 2016). In order to understand if approaches such as these to rebuild consumer trust have been or can be successful, it is necessary that trust is assessed accurately. As previously mentioned, consumer trust is a broad concept 
observable, as a result, numerous items and questions have been created to measure it. Interpersonal trust considers trust as a personality type trait such that individuals are viewed as having a disposition to trust and be trusting of others. For example, "Most people can be counted on to do what they say they will do" (Rotter, 1967). Interpersonal trust has been associated with Genetically Modified (GM) food choices (Ding, Veeman, \& Adamowicz, 2012) and purchase frequency of organic food (Dumortier, Evans, Grebitus, \& Martin, 2017). Meanwhile, other studies have focused directly on trust in food or related areas. Examining trust in GM food, Zhang and colleagues (2018) used two items based on previous research and created two further items to measure trust in factors which might impact upon acceptance of GM foods such as labelling and the media. Perrini and colleagues (2010) measured trust in organic products alongside trust in a retailer, finding a greater level of trust in organic products when sold by a socially responsible retailer. Another study adapted items from the literature to measure perceived levels of care, competence, and openness in actors involved in food safety (de Jonge et al., 2007). Meanwhile Lassoued, Hobbs, Micheels, and Zhang (2015) measured trust in chicken in relation to brand trust and the food industry.

The aforementioned studies measure different types of trust using different items, however, some of these items and scales lack validity and/or reliability suggesting that they may not be scientifically sound. Additionally, while the broad range of items and scales to measure consumer trust is encouraging, the field is fragmented and to the best of our knowledge there exists no single comprehensive collection or toolkit to measure consumer trust along the food chain. As such, the current set of studies aims to develop a valid and reliable food consumer trust toolkit. Researchers can choose items to measure trust along the food chain depending on the focus(es) of their study.

A series of three studies was used to develop and validate questionnaire items to measure consumer trust in food. Each of the studies used an online survey to develop and validate the toolkit. Study one involved a brief review of the literature and generation of the initial pool of relevant items. Study two was used to confirm the findings of study one and reduce and refine the number of items. Study three tested the reliability of the toolkit.

\section{Study $1-$ Critical review of the literature and scale} development

This study commenced with a critical review of the literature to identify existing items and measures relating to consumer trust in food. The following search terms were used in combination across the PsycINFO, Web of Science, and PubMed databases: Consumer 
trust, trust, confidence, food supply chain, food systems, food networks, measur ${ }^{*}$, tool ${ }^{*}$, scale $^{*}$. A total of 9,048 articles were retrieved and assessed for relevance. Duplicate and irrelevant articles (such as those which did not contain a measurement of trust) were removed, leading to an in-depth review of 40 full text articles. A further manual search of the grey literature and publication lists of known authors in the field led to the inclusion of an additional five articles. The most commonly used items and scales were collated and critiqued by four researchers in the areas of food quality, safety, and nutrition (TB, FL, MS, $M D)$. Items were selected based upon their frequency of use within the literature, face validity, and any other validity or reliability testing which had been conducted. These selected items were then administered to participants using an online survey (for further information, see section 2.1). This study aimed to generate an initial pool of items that could be used to measure consumer trust.

\subsection{Method}

\section{Trust items}

Following the critical review, those items identified as most appropriate and relevant by the researchers were included in the initial pool of consumer trust items $(n=54)$. All items were measured on a seven point scale ranging from 1 (strongly disagree) to 7 (strongly agree). Overall, the items spanned five levels of the food chain, ranging from the general to the specific:

- Interpersonal trust. Trust at the individual level. How trusting an individual is in general as a person. Example item: "Most people are basically good and kind".

- General organisation trust. Trust at the organisation level. How much an individual trusts a certain organisation (related to food but not involved in the food chain) in general. Example item: "<organisation> is dependable"

- Specific organisation trust. How much an individual trusts an organisation in terms of a specific area or to perform a specific task. Example item: "<organisation> are good at looking at the evidence and judging what to do".

- Food chain trust. How much an individual trusts the actors or organisations involved in food production. Example item: "<organisation/actor> has the competence to control the safety of food".

- Product trust. How much an individual trusts a specific product. Example item: "<product $>$ is trustworthy". 
Participants and procedure

Individuals were invited to participate in the survey by a research agency from their online panel of UK consumers in October 2018. Individuals completed a series of screening questions to assess their eligibility to take part in the study. To avoid bias, anyone working in (or living in a household with anyone working in) food safety, food processing or manufacturing as well as the farming, growing, wholesale or retail of food or drinks were excluded. Those aged under 18 were also excluded. Quotas were applied to achieve a nationally representative UK sample in terms of age, gender, and region. The final sample number was 481 , with individuals ranging in age from 18 to 92 years old $(M=46.64, S D=$ 17.06) (Table 1). Participants completed sociodemographic items followed by the trust items for each type of trust. While we believed that that the trust items could be applied to any organisation, product, or food chain actor, in this survey we used the European Food Safety Authority (EFSA) as the organisation, beef burgers as the product, and food manufacturers as the food chain actor. EFSA was defined to participants as an organisation which 'provides independent scientific advice about food risks and food safety to the public and decision makers who regulate food safety in Europe'. To ensure no missing data, a forced response option was used for all items. The questionnaire took approximately 20 minutes to complete. Ethical approval (10/18/BensonT) was granted by the Queen's University Belfast School of Biological Sciences Research Ethics Committee. The study was conducted in accordance with the Declaration of Helsinki and informed consent was obtained.

Data analysis

Prior to data analysis, where necessary, items were reversed coded so that a higher score indicated greater trust for all items. Exploratory factor analysis (principal axis factoring) with direct oblimin rotation was used. This oblique rotation was used as it was believed that the factors (types of trust) would be related (Yong \& Pearce, 2013). For example, if someone has a high level of interpersonal trust and is a trusting person, one would expect they will also have a high level of trust in other areas. Each iteration of the factor analysis was refined using cut-off criteria outlined below until an optimal solution was reached. All analyses were conducted using IBM SPSS Statistics v25. 


\subsection{Results}

The results showed an excellent Kaiser-Meyer-Olkin (KMO) value of 0.95 (Kaiser, $1974)$ and a significant $(p<.001)$ Bartlett's Test of Sphericity, indicating that the sample was adequate for factor analysis (Field, 2009). Eight factors were apparent in the data, as shown by Eigenvalues greater than 1 (Kaiser, 1960). However, one factor had no items which loaded highest upon this factor and another factor contained only two items which loaded highest upon it. In general, each factor should contain at least three items (Carpenter, 2018). Given this, the analysis was conducted again with the instruction to extract six factors only.

In order to evaluate the six factor solution and reduce the number of items, the following criteria were used: No factors with fewer than three items (Carpenter, 2018), no

212 items which cross-loaded greater than 0.3 across factors, no items with communality less

213 than 0.3 , and no items with corrected item scale correlation less than 0.3 (Worthington \&

214 Whittaker, 2006). Typically, items with factor loadings less than 0.3 or 0.4 are also removed

215 (Worthington \& Whittaker, 2006). However, given the relatively small number of items removed using the aforementioned criteria and the need to further reduce the number of items in the scale at this stage, as well as the suggestion that the factor loading cut-off should be set as high as possible (Worthington \& Whittaker, 2006), it was decided to use a more stringent minimum factor loading of 0.6. Items were removed only if they improved or did not reduce the reliability (Cronbach's Alpha) of that factor. In total, 9 items were removed, leaving 45 items.

The remaining items were subjected to a final exploratory factor analysis to ensure that the factor structure and results were acceptable following the previous modifications. All factors contained at least three items, no items cross-loaded on more than one factor, and the minimum factor loading was 0.6 . In addition, the internal reliability values for each scale (Cronbach's Alpha) were above the typical cutoff value of 0.6-0.7 (Hair, Black, Babin, \& Anderson, 2014), therefore, all 45 items were retained. A review of the factors and their associated items suggested that factor 1 related to trust in organisations; factor 2 related to product trust; factor 3 interpersonal trust; factor 4 trust in the food chain; factor 5 organisation distrust; and factor 6 interpersonal distrust.

\subsection{Discussion}

Study one collated items measuring consumer trust relating to the area of food. 
loading, suggesting defined and distinct factors. While it was hypothesised that the data would lead to five factors, six factors emerged. As expected, interpersonal trust, food chain trust, and product trust were apparent as separate factors in the data. However, specific organisation trust appeared to merge with general organisation trust, suggesting that consumers may not distinguish between the two. Unexpectedly, two distrust factors were identified in the data - interpersonal distrust and organisation distrust. The next step was to confirm these findings using a larger sample.

\section{Study 2 - Confirmation and validation of factorial structure}

Following the establishment of the factor structure in study 1, study 2 aimed to confirm these findings in a larger sample. A number of other scales and measures were included in this study to allow for validation testing of the trust toolkit, these are outlined in section 3.1.

247

\subsection{Method}

249 Trust items

250 The final set of 45 trust items from study 1 were included in study 2 . These were unchanged, with items measured on a scale ranging from 1 (strongly disagree) to 7 (strongly agree) and spanning the six factors (types of trust) identified in study 1: trust in organisations; product trust; interpersonal trust; trust in the food chain; organisation distrust; interpersonal distrust.

\section{Established item measuring interpersonal trust}

A single item commonly used to measure interpersonal trust in the literature was included in addition to the 45 trust items: "Generally speaking, would you say that most people can be trusted, or that you can't be too careful in dealing with people?" (European Social Survey, 2012). This was measured on an 11 point scale $(0=$ you can't be too careful, $10=$ most people can be trusted). This item was included to examine the convergent validity of the interpersonal trust factor.

Life satisfaction was measured with a single item (Office for National Statistics, 
267 (not at all satisfied) to 10 (completely satisfied). This item was included to examine the 268 convergent validity of the interpersonal trust factor.

\section{Food safety information seeking}

To measure to what extent individuals were interested in seeking information relating

272 to food safety risks, participants were asked to select all types of information which they

273 would like to receive if new risks to food safety were discovered (adapted from Etienne,

274 Chirico, McEntaggart, Papoutsis, \& Millstone, 2018). Examples of information sources

275 included 'general description of the risk' and 'technical or scientific details'. The number of

276 information sources that participants selected (ranging from 0 to 7 ) was used as a score to

277 indicate how interested the individual is in seeking information related to food safety, with a

278 higher score indicating greater interest. These items were included to examine the

279 convergent validity of the organisation trust factor.

280

\section{Corporate distrust scale}

General distrust in organisations was measured using items from the corporate distrust scale (Adams, Highhouse, \& Zickar, 2010). The most relevant items (seven items) were adapted so that EFSA was defined as the example organisation/corporation, as was the case with the items measuring trust in organisations. Items in this scale included 'EFSA do not accept accountability for their actions' and 'EFSA intentionally deceives the public'. These items were included to examine the convergent validity of the organisation trust factor.

Frequency of buying

Individuals were asked approximately how often they purchase beef burgers (the chosen product used for the items measuring product trust) using a scale from 1 (never) to 9 (once or more a day). This item was included to examine the convergent validity of the

\section{Food quality interest}

To measure interest in food quality, three items were adapted from the general health interest scale (Roininen, Lähteenmäki, \& Tuorila, 1999): 'The quality of food has little impact on my food choices' 'I am very particular about the quality of food I eat' and 'I eat what I like and do not worry about the quality of food'. These items were selected as the most relevant to measure interest in food quality, with other items in the scale measuring healthiness and nutrients. Each item was measured on a seven point scale ranging from strongly disagree to 
strongly agree. These items were included to examine the convergent validity of the product trust factor.

305

\section{Participants and procedure}

As with study 1, a research agency invited potential participants from their online panel of consumers to partake in the study (in November 2018). To ensure that the developed trust toolkit had cross-cultural relevance, individuals from countries with varying levels of trust were invited to participate. The 2018 Edelman Trust Barometer (Edelman,

311 2018) and the Eurobarometer 354 (European Food Safety Authority, 2010) were used to select countries according to their levels of general trust and levels of confidence in organisations related to food such as EFSA. Using these sources, the UK was chosen as a country to sample as it has the lowest level of trust in general (alongside Ireland) in Europe, and amongst the lowest levels of confidence in Europe for organisations related to the food chain. Finland was chosen as a country high in confidence in organisations relating to the food chain. Nordic countries (and particularly Finland) typically have a high level of trust for issues relating to food (Jokinen, Kupsala, \& Vinnari, 2012). Germany is typically amongst either the lowest or highest ranking countries in Europe for confidence depending on the food-related organisation and has an average level of trust in general amongst European countries. Greece was chosen to be sampled as it is a Southern European country in contrast to the aforementioned Northern European countries and this may be reflected in differing attitudes to food. For example, individuals in Greece have high levels of concern for food production and quality (European Commission, 2012) Individuals under the age of 18 or those working in (or living in a household with anyone working in) food safety, food processing or manufacturing as well as the farming, growing, wholesale or retail of food or drinks were excluded from participation. The final samples for each country were approximately representative in terms of age, gender, and region (maximum $+/-8 \%$ difference between population figures and sample achieved). In total, 1,027 individuals participated (UK $n=256$; Germany $n=257$; Finland $n=253$, Greece $n=253)$. The mean age was $46.99(S D=16.95$, range $=18$ to 85$)$ (Table 2). 
Prior to the rollout of the survey, all questions and instructions were translated into the primary language of each sample country by native speakers. These translations were then proofread by a second native speaker and quality assured by a third linguist before being confirmed by the project manager (also a trained linguist). As with survey 1, EFSA was specified as the organisation for items measuring organisation trust, beef burgers were specified as the product for items measuring product trust, and food manufacturers were specified as the actor in the chain for items measuring trust in the food chain. Participants completed sociodemographic details then the 45 trust items followed by the remaining items. Each item in the survey used a forced response option to ensure no missing data. The questionnaire took approximately 20 minutes to complete. Ethical approval (10/18/BensonT) was granted by the Queen's University Belfast School of Biological Sciences Research Ethics Committee. The study was conducted in accordance with the Declaration of Helsinki and informed consent was obtained.

Data analysis

The initial step in data analysis involved recoding any reverse scored items. The final model identified in study one was entered into IBM SPSS Amos v25 as a confirmatory factor analysis model with maximum-likelihood estimation. This model was then assessed and amended according to various model fit statistics. Following their review of the literature, Hinkin and colleagues (1997) outline several fit statistics typically used to evaluate models.

- Chi-square $\left(x^{2}\right)$ - A non-significant chi-square value $(p>0.05)$ which is, at a maximum, two or three times larger than its value divided by the degrees of freedom (df) indicates that the model can be accepted

- Root Mean Square Error of Approximation (RMSEA) - A value of 0.05 or less is optimal

- Comparative Fit Index (CFI) - A value of 0.90 or greater indicates that the model can be accepted

- Normed-Fit Index (NFI) - A value of 0.90 or greater indicates that the model can be accepted

- Tucker-Lewis Index (TLI) - A value of 0.90 or greater indicates that the model can be accepted

Following the use of fit statistics and modification indices to refine and select the most appropriate model, several validation tests were conducted. Face validity is used to ensure that the items under each factor measure what they claim to measure 'at face value'. 
371 Convergent validity shows that measures are valid by identifying a relationship with an

372 existing similar measure using correlation analysis. A further method of identifying

373 convergent validity is to examine the Average Variance Extracted (AVE) of each scale (a

374 summary indicator of convergence). An AVE value of 0.5 or more is considered acceptable

375 (Hair et al., 2014). Discriminant validity refers to a scale or measure being distinct from other

376 constructs. Discriminant validity is present when the square root of the AVE is greater than

377 the correlation between the scale and other scales in the model (Hair et al., 2014).

378 Discriminant validity is also present if the Maximum Squared Variance (MSV) is less than the

379 AVE for each scale (Rebelo-Pinto, Pinto, Rebelo-Pinto, \& Paiva, 2014).

380

381

\subsection{Results}

382

Model refinement

383

Initial fit statistics showed that the model retained from survey 1 was acceptable (see

Table 3). The chi-square value was significant and greater than 2-3 times larger than the $\mathrm{X}^{2} / \mathrm{df}$, however, this fit statistic is known to be sensitive to large sample sizes such as that in the current study. While the RMSEA value was greater than 0.05 , this was still acceptable at 0.08 (Hooper, Coughlan, \& Mullen, 2008). The CFI, NFI, and TLI were all acceptable at approximately 0.90 .

While the modification indices were examined for potential improvements to model fit, no changes were made as these were not justifiable by theory or rationale. However, two of the factors (organisation distrust and interpersonal distrust) consisted of only negatively worded items. Past research on scale development has found that the inclusion of negatively worded items in a scale or questionnaire may lead to spurious factors containing only these items (X. Zhang, Noor, \& Savalei, 2016). This is due to a method effect and the manner in which participants respond to negative items, rather than these items representing true factors. To test for methods effects, two further models (models 2 and 3 ) were created 397 (Table 3).

Model 2 was a modification of model 1 which allowed the error terms of the negatively worded items to covary. This produced similar results to those of model 1 . Model

4023 was also a modification of model 1, which allowed the error terms of the positively worded items to covary. The results of this model were also acceptable. 
405 This is perhaps unsurprising given the large number of positively worded items and therefore 406 large number of modifications made to the model to allow the error terms to covary. Fit 407 statistics provide guidance as to the acceptability of each model, however, theory and 408 parsimony are also important considerations in model selection. Given this, and that the 409 results show that the improvement in fit of model 3 over models 1 and 2 was marginal, 410 model 1 was established as the most relevant, parsimonious, and acceptable model for the 411 data. All items loaded well on their respective factors, with a minimum item loading in the 412 model of 0.6 (Figure 1). The final items can be seen in Table 4.

413

$<$ Insert Figure 1 about here $>$

415 
417 Face validity

418 To ensure that the toolkit had face validity, four consumer researchers in the areas of

419 food quality, safety, and nutrition (TB, FL, MS, MD) reviewed the final model. All items were

420 examined to ensure that they measured what they claim to measure. It was agreed that all

421 items were appropriate for their factor (type of trust) and that no items were too similar or

422 measured more than one type of trust. Therefore, face validity was established.

423 Convergent validity

424 Convergent validity was examined by comparing the relationships between the trust 425 measures and other existing scales or variables which have been previously linked with 426 trust. Spearman's rank correlation analyses showed that the trust measures in the current 427 study were significantly correlated with existing related items as expected (Table 5). For 428 example, frequency of buying was linked with product trust - the more one trusts a product, 429 the more likely they are to buy that product. Therefore, convergent validity of each trust 430 factor and the toolkit was established. Convergent validity of the toolkit was further 431 established as none of the trust factors had an AVE of below 0.5 (minimum AVE 0.53 432 results not shown).

Discriminant validity

Initial evidence of discriminant validity was seen in the factor loadings in the CFA in the current study and EFA in study one. None of the items cross-loaded on to more than one factor or type of trust. Table 6 also shows evidence of discriminant validity as the square root of the AVE for each trust factor is greater than the correlation between that factor and the other trust factors. The MSV was also less than the AVE for each factor, further indicating discriminant validity.

442

$<$ Insert Table 6 about here>

444

\subsection{Discussion}

446 The purpose of study two was to confirm the structure and test the validity of the scales 447 developed in the previous study. Given the emergence of two unexpected distrust factors in 448 study one, the current study began by using confirmatory factor analysis to develop models 449 to test whether these distrust factors may have emerged due to methods effects, as a result 450 of individuals responding differently to these items as they were negatively worded. While 
the results suggested some improvement in model fit when methods effects were addressed, this was likely as a result of the large number of modifications made to the model. It is therefore suggested that the two distrust factors are true factors and not due to methods effects and patterns of responding. Given the parsimony of the initial confirmed model from study one, this was accepted as the final model.

Results of the validity testing suggest that the toolkit has face, convergent, and discriminant validity. Furthermore, the use of four countries in the sample suggests that the toolkit may be applied across different countries and cultures.

459

\section{Study 3 - Reliability testing}

Following the development and validation of the factor structure of the toolkit, study 3 was designed to assess the reliability of the scales. Both composite and test-retest reliability of the scales were examined.

464

465

\subsection{Method}

466

\section{Participants and procedure}

All participants who fully completed study 2 were re-contacted two weeks after completion to invite participation in study 3 . The study took place in November and December 2018. In total, 247 participants were recruited across the four countries (UK $n=$

47159 , Finland $n=60$, Germany $n=58$, and Greece $n=70)$, the mean age was 50.64 ( $S D=$ 16.35 , range $=18$ to 65$)($ Table 7$)$.

473

Participants completed only the 45 questionnaire items relating to trust. These were the same 45 items included in study 2 . Each item used a forced response option, leading to no missing data. The questionnaire took approximately 10 minutes to complete. Ethical approval (10/18/BensonT) was granted by the Queen's University Belfast School of Biological Sciences Research Ethics Committee. The study was conducted in accordance with the Declaration of Helsinki and informed consent was obtained. 
Each participant's data from study 2 and study 3 were matched using an anonymised code. Where necessary, any reverse scored items were then recoded. Composite (internal) reliability was used to examine agreement between the items in a scale. The composite reliability value for each scale was calculated using the standardised factor loadings of items and their respective error variances. A value of 0.7 or higher shows good reliability (Hair et al., 2014)

The temporal stability of the scales was examined using the Intra-class Correlation Coefficient (ICC). This shows the level of agreement between item answers over a time period (in this case at least two weeks between study 2 and the current study). A stronger ICC indicates greater agreement between answers and therefore suggests greater temporal stability. An ICC value of 0.50-0.75 indicates moderate reliability, a value of $0.75-0.90$ indicates good reliability, while a value of greater than 0.90 suggests excellent reliability (Koo \& Li, 2016). All analyses were conducted using IBM SPSS Statistics v25.

\subsection{Results}

Table 8 shows the results for the reliability of the toolkit scales. The minimum composite reliability value was 0.82 , above the acceptable level of 0.70 . In terms of temporal stability, all scales had either moderate (ICC value $0.50-0.75$ ) or good (ICC value $0.75-$ $0.90)$ reliability.

503

\subsection{Discussion}

Study three showed that the scales in the trust toolkit were reliable. This was both in terms of internal reliability and a good level of agreement between the items in each scale, and temporal stability with a good level of agreement between each participant's scores over time.

\section{General discussion} goods purchased are authentic, safe, and of satisfactory quality. Food safety incidents and 
515 modernisation in the food supply chain have arguably not only led to decreases in consumer

516 trust, but have also simultaneously led to a growing importance in trust as consumers

517 become further distanced from development and production. In order to understand if

518 attempts to improve consumer trust are successful, it is necessary to have a valid and

519 reliable method of measuring trust. While a plethora of studies have measured different

520 aspects of consumer trust in relation to food, many of the measures developed lack

521 validation and/or reliability. In order to ensure that changes following efforts to increase

522 consumer trust represent true effects, validation and reliability of scales are vital. The aim of

523 the current set of studies was to develop and test a consumer trust toolkit consisting of items

524 which can be used to measure consumer trust in relation to various actors or aspects of the

525 food system. The results suggest that the scales developed contain accurate items which

526 may be used to measure different aspects of consumer trust.

527 A review of the literature suggested that there were five different types of trust

528 relating to the food chain: Interpersonal trust, general organisation trust, specific organisation

529 trust, food chain trust, and product trust. However, results from our exploratory factor

530 analysis suggested six different factors: Interpersonal trust, organisation trust, food chain

531 trust, product trust, interpersonal distrust, and organisation distrust. Inspection of the factors

532 showed that those items we believed measured specific trust in organisations grouped

533 together with those items we believed measured (general) organisation trust. This suggests

534 that consumers do not distinguish between general trust in organisations and trust in

535 organisations to perform certain tasks. That is, if an individual trusts an organisation in

536 general, then this trust appears to extend to trust in their ability to perform any specific tasks.

537 In the literature, trust is separated into general versus specific trust, where general trust is

538 referred to as interpersonal trust or a personality trait and specific trust as trust in a specific

539 entity or object (Stefani, Cavicchi, Romano, \& Lobb, 2008). Referring back to the definition of

540 trust provided in the introduction as "the willingness of a party to be vulnerable to the actions

541 of another party based on the expectation that the other will perform a particular action

542 important to the trustor, irrespective of the ability to monitor or control that other party"

543 (Mayer et al., 1995), it is logical that specific trust relates to a specific entity rather than a

544 specific task. This indistinguishable link between general trust in an organisation and trust in

545 the organisation's ability to perform certain tasks means that entities involved in food

546 production and supply have some flexibility with regards to their actions, as these are trusted

547 by the consumer. When an organisation's tasks or actions are considered to be honest and

548 sincere, this may produce a halo effect of improving the general trust in that organisation.

549 A further interesting finding from the results was the identification of two distrust

550 factors - interpersonal distrust and organisation distrust. This was unexpected given that we 
did not believe that any items in the questionnaire measured distrust. However, several items measuring trust were negatively worded, that is, they differed in their wording compared to most other items in the questionnaire. An example of a positively worded item was "most people are trustworthy" while a negatively worded item was "you can't trust strangers anymore". The inclusion of negatively worded items is designed to reduce acquiescence error or bias, when a participant answers affirmatively to all items regardless of content (Hinz, Michalski, Schwarz, \& Herzberg, 2007). For example, if a participant answers ' 7 ' on a scale of 1 to 7 on both all positive and negative items, one may infer the participant did not attend to or understand the items as these assess very different opinions. With regards to questionnaire development, recent research suggests that the inclusion of negative items may lead to the formation of a methods factor based on how participants respond rather than a 'true' factor (X. Zhang et al., 2016). In study 2, the use of CFA allowed for the examination of potential methods effects. While the models accounting for methods effects showed marginal improvements in model fit over the standard model, this may have been due to the large number of modifications made to the revised models to account for potential methods effects. That the negative items loaded on to two factors as opposed to one factor suggests that methods effects may not be the only explanation. The body of evidence recognising that trust and distrust are related yet distinct concepts (Cho, 2006; Lee et al., 2018; Lewicki, McAllister, \& Bies, 1998; McKnight, Kacmar, \& Choudhury, 2004) also supports our contention that the distrust factors in the current studies emerged due to a conceptual difference between trust and distrust rather than methods effects. However, given the unequal and limited number of negatively worded items compared to positive items, as well as the use of negatively worded items for only some types of trust, we were unable to investigate this fully. Future research might investigate this issue further for the different types of trust and using an equal number of positively and negatively worded items. Future studies in this area should be aware of the implications of using negatively worded trust items or reverse wording trust items. This may lead to measuring the different concept of distrust rather than trust. Furthermore, the inclusion of both positively and negatively worded items may cause additional issues with regards to respondent confusion and consistency (Colosi, 2005; Salazar, 2015).

The final factor model details a rational and logical solution supported by the data. All items load effectively on one factor only and the relationships between factors shows distinct but related concepts. Relationships between the factors are as would be expected. For example, product trust has a stronger relationship with chain trust and organisation trust than the other types of trust. Multiple different types of validity tests were conducted and the use of different methods to assess each type of validity as well as reliability testing is a particular 
587

588

589

590

591

592

593

594

595

596

597

598

599

600

601

602

603

604

605

606

607

608

609

610

611

612

613

614

615

616

617

618

619

strength of the current set of studies. The sampling and testing of multiple countries with varying levels of trust according to previous research means that the toolkit has broad application. The use of a relatively large sample size for factor analysis and testing was also a strength.

A limitation of the current study was the use of an EU only sample. As such, in addition to testing for further methods effects, future studies should sample other countries. This is particularly pertinent given that trust can vary widely between countries in the East and West (Krockow, Takezawa, Pulford, Colman, \& Kita, 2017; Yamagishi \& Yamagishi, 1994). In countries outside the EU, information on food and safety or quality may be provided by those involved in the chain such as manufacturers and retailers rather than an independent organisation related to the chain such as EFSA. While the toolkit measures trust in those involved in the chain, it does not specifically assess trust in information provided by those in the chain. The toolkit was created with the aim of being adaptable to various specific aspects of the food system such as different products and actors within the chain. While we used specific examples such as EFSA, food manufacturers, and beef burgers in the items used in the studies, we created the toolkit to be adaptable and believe the items in the toolkit can be applied to different specific aspects of the food system such as different products and actors. Future research should examine how the validity and reliability of the toolkit is affected by using different specifics. Finally, the accuracy of the toolkit might also be tested in further studies by using the toolkit to measure baseline trust, intervening to increase trust then measuring again using the toolkit to see if there has been a resulting increase in trust.

\section{Conclusions}

The consumer trust toolkit is a valid and reliable collection of items to measure trust in the food system. Drawing upon previous research, the toolkit contains items to measure trust in various levels of the food system from production through to consumption. Given the relatively modular nature of the toolkit, researchers in this area can use a specific collection of items to measure trust depending upon which aspects they are most interested.

Consumer trust in food is currently low and the toolkit can be used in future studies to identify the most effective methods to improve trust. 
620 Funding

621 This work was supported by EIT Food, the innovation community on Food of the European

622 Institute of Innovation and Technology, a body of the European Union, under Horizon 2020,

623 the EU Framework Programme for Research and Innovation [grant number 18021]. The

624 funding body had no role in the design of the study; in the collection, analyses, or

625 interpretation of the data; in the writing of the manuscript, and in the decision to submit the 626 article for publication.

627

628

629 Declarations of interest

630 None

631 
638

639

640

641

642

643

644

645

646

647

648

649

650

651

652

653

654

655

656

657

658

659

660

661

662

663

664

665

666

667

668

669

670

671

672

673

674

675

676

677

678

679

680

681

\section{References}

Adams, J. E., Highhouse, S., \& Zickar, M. J. (2010). Understanding general distrust of corporations. Corporate Reputation Review, 13(1), 38-51. JOUR. http://doi.org/10.1057/crr.2010.6

Allum, N. (2007). An empirical test of competing theories of hazard $\square$ related trust: The case of GM food. Risk Analysis: An International Journal, 27(4), 935-946. JOUR.

Ariyawardana, A., Ganegodage, K., \& Mortlock, M. Y. (2017). Consumers' trust in vegetable supply chain members and their behavioural responses: A study based in Queensland, Australia. Food Control, 73, 193-201. JOUR.

Berg, L. (2004). Trust in food in the age of mad cow disease: a comparative study of consumers' evaluation of food safety in Belgium, Britain and Norway. Appetite, 42(1), 21-32.

Bozic, B. (2017). Consumer trust repair: A critical literature review. European Management Journal, 35(4), 538-547.

Brudvig, S. (2015). Consumer-based brand trust scales: validation and assessment. In Revolution in Marketing: Market Driving Changes (pp. 17-21). CHAP, Springer.

Bruschi, V., Shershneva, K., Dolgopolova, I., Canavari, M., \& Teuber, R. (2015). Consumer perception of organic food in emerging markets: evidence from Saint Petersburg, Russia. Agribusiness, 31(3), 414-432.

Carpenter, S. (2018). Ten steps in scale development and reporting: A guide for researchers. Communication Methods and Measures, 12(1), 25-44.

Cho, J. (2006). The mechanism of trust and distrust formation and their relational outcomes. Journal of Retailing, 82(1), 25-35. http://doi.org/10.1016/J.JRETAI.2005.11.002

Colosi, R. (2005). Negatively Worded Questions Cause Respondent Confusion. In Annual Meeting American Statistical Association (pp. 2896-2903). Minneapolis, MN. Retrieved from http://citeseerx.ist.psu.edu/viewdoc/download?doi=10.1.1.556.243\&rep=rep1\&ty pe $=p d f$

Connolly, R., \& Bannister, F. (2007). Consumer trust in Internet shopping in Ireland: towards the development of a more effective trust measurement instrument. Journal of Information Technology, 22(2), 102-118.

Coveney, J., Henderson, J., Mayer, S., Mamerow, L., Taylor, A., Ward, P., \& Wilson, A. (2015). Consumer Trust. In K. Albala (Ed.), The SAGE Encyclopedia of Food Issues (First, pp. 282-285). Thousand Oaks, CA, CA: Sage Publications Sage CA: Thousand Oaks, CA.

De Jonge, J., Van Trijp, H., Jan Renes, R., \& Frewer, L. (2007). Understanding consumer confidence in the safety of food: Its two $\square$ dimensional structure and determinants. Risk Analysis, 27(3), 729-740. JOUR.

de Jonge, J., van Trijp, J. C. M., van der Lans, I. A., Renes, R. J., \& Frewer, L. J. (2008). How trust in institutions and organizations builds general consumer confidence in the safety of food: A decomposition of effects. Appetite, 51(2), 311-317. http://doi.org/10.1016/J.APPET.2008.03.008

Ding, Y., Veeman, M. M., \& Adamowicz, W. L. (2012). The impact of generalized trust and trust in the food system on choices of a functional GM food. Agribusiness, 28(1), 54-66.

Dumortier, J., Evans, K. S., Grebitus, C., \& Martin, P. A. (2017). The influence of trust and attitudes on the purchase frequency of organic produce. Journal of 
International Food \& Agribusiness Marketing, 29(1), 46-69.

Edelman. (2018). 2018 Edelman Trust Barometer: Global Report. Retrieved from https://www.edelman.com/sites/g/files/aatuss191/files/201810/2018_Edelman_Trust_Barometer_Global_Report_FEB.pdf

Etienne, J., Chirico, S., McEntaggart, K., Papoutsis, S., \& Millstone, E. (2018). EU Insights - Consumer perceptions of emerging risks in the food chain. EFSA Supporting Publications, 15(4), 1394E. JOUR. http://doi.org/10.2903/sp.efsa.2018.EN-1394

European Commission. (2012). Special Eurobarometer 389: EUROPEANS' ATTITUDES TOWARDS FOOD SECURITY, FOOD QUALITY AND THE COUNTRYSIDE. Retrieved from http://ec.europa.eu/commfrontoffice/publicopinion/archives/ebs/ebs_389_en.pdf

European Food Safety Authority. (2010). SPECIAL EUROBAROMETER 354: Foodrelated risks. Parma: Italy. Retrieved from http://ec.europa.eu/commfrontoffice/publicopinion/archives/ebs/ebs_354_en.pdf European Social Survey. (2012). ESS Round 6 Source Questionnaire. London. Retrieved from https://www.europeansocialsurvey.org/docs/round6/fieldwork/source/ESS6_sour ce_main_questionnaire.pdf

Field, A. (2009). Discovering Statistics Using SPSS (Second). London, UK: Sage Publications.

Frewer, L. J., \& Miles, S. (2003). Temporal stability of the psychological determinants of trust: Implications for communication about food risks. Health, Risk \& Society, 5(3), 259-271.

Frewer, L. J., Scholderer, J., \& Bredahl, L. (2003). Communicating about the risks and benefits of genetically modified foods: The mediating role of trust. Risk Analysis: An International Journal, 23(6), 1117-1133. JOUR.

Fritz, M., Martino, G., \& Surci, G. (2008). Trust conditional on governance structure: theory and evidence from case studies. Journal on Chain and Network Science, 8(1), 33-46.

Giampietri, E., Verneau, F., Del Giudice, T., Carfora, V., \& Finco, A. (2018). A Theory of Planned behaviour perspective for investigating the role of trust in consumer purchasing decision related to short food supply chains. Food Quality and Preference, 64, 160-166.

Gurviez, P., \& Korchia, M. (2003). Proposal for a multidimensional brand trust scale. In 32nd Emac-Conference-Glasgow, Marketing: Responsible and Relevant (pp. 438-452). CONF.

Hair, J. F., Black, W. C., Babin, B. J., \& Anderson, R. E. (2014). Multivariate Data Analysis (Seventh). Essex: Pearson Education.

Hinkin, T. R., Tracey, J. B., \& Enz, C. A. (1997). Scale Construction: Developing Reliable and Valid Measurement Instruments. Journal of Hospitality \& Tourism Research, 21(1), 100-120. http://doi.org/10.1177/109634809702100108

Hinz, A., Michalski, D., Schwarz, R., \& Herzberg, P. Y. (2007). The acquiescence effect in responding to a questionnaire. Psycho-Social Medicine, 4, Doc07. Retrieved from http://www.ncbi.nlm.nih.gov/pubmed/19742288

Hobbs, J. (2011). Recovering consumer confidence after a food crisis. Advances in Pork Production, 22, 217-224.

Hooper, D., Coughlan, J., \& Mullen, M. (2008). Structural equation modelling: Guidelines for determining model fit. Articles, 2.

Jin, S., \& Zhou, L. (2014). Consumer interest in information provided by food 
traceability systems in Japan. Food Quality and Preference. http://doi.org/10.1016/j.foodqual.2014.04.005

Jokinen, P., Kupsala, S., \& Vinnari, M. (2012). Consumer trust in animal farming practices - exploring the high trust of Finnish consumers. International Journal of Consumer Studies, 36(1), 106-113. http://doi.org/10.1111/j.14706431.2011.00996.x

Kaiser, H. F. (1960). The application of electronic computers to factor analysis. Educational and Psychological Measurement, 20(1), 141-151.

Kaiser, H. F. (1974). An index of factorial simplicity. Psychometrika, 39(1), 31-36.

Kendall, H., Naughton, P., Kuznesof, S., Raley, M., Dean, M., Clark, B., ... Zhong, Q. (2018). Food fraud and the perceived integrity of European food imports into China. PloS One, 13(5), e0195817. JOUR.

Koo, T. K., \& Li, M. Y. (2016). A guideline of selecting and reporting intraclass correlation coefficients for reliability research. Journal of Chiropractic Medicine, 15(2), 155-163.

Krockow, E. M., Takezawa, M., Pulford, B. D., Colman, A. M., \& Kita, T. (2017). Cooperation and trust in Japanese and British samples: Evidence from incomplete information games. International Perspectives in Psychology: Research, Practice, Consultation, 6(4), 227-245. http://doi.org/10.1037/ipp0000074

Lassoued, R., Hobbs, J. E., Micheels, E. T., \& Zhang, D. Di. (2015). Consumer Trust in Chicken Brands: A Structural Equation Model. Canadian Journal of Agricultural Economics/Revue Canadienne d'agroeconomie, 63(4), 621-647. http://doi.org/10.1111/cjag.12082

Lee, S.-J., Ahn, C., Song, K. M., Ahn, H., Lee, S.-J., Ahn, C., ... Ahn, H. (2018). Trust and Distrust in E-Commerce. Sustainability, 10(4), 1015. http://doi.org/10.3390/su10041015

Lewicki, R. J., McAllister, D. J., \& Bies, R. J. (1998). Trust and distrust: New relationships and realities. Academy of Management Review, 23(3), 438-458.

Liu, R., Gao, Z., Nayga Jr, R. M., Snell, H. A., \& Ma, H. (2019). Consumers' valuation for food traceability in China: Does trust matter? Food Policy, 88, 101768.

Lu, J., Wu, L., Wang, S., \& Xu, L. (2016). Consumer preference and demand for traceable food attributes. British Food Journal, 118(9), 2140-2156.

MacLeod, H. (2013). Views on the horsemeat scandal. Retrieved December 3, 2018 , from https://yougov.co.uk/topics/consumer/articles-reports/2013/02/15/viewshorsemeat-scandal

Mayer, R. C., Davis, J. H., \& Schoorman, F. D. (1995). An integrative model of organizational trust. Academy of Management Review, 20(3), 709-734.

McKnight, D. H., Kacmar, C. J., \& Choudhury, V. (2004). Dispositional trust and distrust distinctions in predicting high-and low-risk internet expert advice site perceptions. E-Service, 3(2), 35-58.

Meixner, O., Ameseder, C., Haas, R., Canavari, M., Fritz, M., \& Hofstede, G. J. (2009). Importance of trust building elements in business-to-business agri-food chains. Journal of Farm Management, 13(9), 655-668.

Menozzi, D., Halawany-Darson, R., Mora, C., \& Giraud, G. (2015). Motives towards traceable food choice: A comparison between French and Italian consumers. Food Control, 49, 40-48.

Miran, B., \& Akgüngör, S. (2005). The effect of mad cow (BSE) scare on beef demand and sales loss: The case of Izmir. Turkish Journal of Veterinary and 

Animal Sciences, 29(2), 225-231.

Moorman, C., Deshpande, R., \& Zaltman, G. (1993). Factors affecting trust in market research relationships. Journal of Marketing, 57(1), 81-101.

Morgan, R. M., \& Hunt, S. D. (1994). The commitment-trust theory of relationship marketing. Journal of Marketing, 58(3), 20-38.

Nuttavuthisit, K., \& Thøgersen, J. (2017). The importance of consumer trust for the emergence of a market for green products: The case of organic food. Journal of Business Ethics, 140(2), 323-337. JOUR.

Office for National Statistics. (2015). Measuring National Well-being - Office for National Statistics. Retrieved April 29, 2019, from https://www.ons.gov.uk/peoplepopulationandcommunity/wellbeing/bulletins/mea suringnationalwellbeing/2015-09-23

Perrini, F., Castaldo, S., Misani, N., \& Tencati, A. (2010). The impact of corporate social responsibility associations on trust in organic products marketed by mainstream retailers: a study of Italian consumers. Business Strategy and the Environment, 19(8), 512-526. JOUR.

PriceWaterhouseCoopers. (2015). Food trust - Giving customers confidence in your food. Delaware, Belfast. Retrieved from https://www.pwc.nl/nl/assets/documents/pwc-food-supply-and-integrityservices.pdf

Rebelo-Pinto, T., Pinto, J. C., Rebelo-Pinto, H., \& Paiva, T. (2014). Validation of a three-dimensional model about sleep: Habits, personal factors and environmental factors. Sleep Science, 7(4), 197-202. http://doi.org/10.1016/J.SLSCI.2014.12.002

Roininen, K., Lähteenmäki, L., \& Tuorila, H. (1999). Quantification of consumer attitudes to health and hedonic characteristics of foods. Appetite, 33(1), 71-88.

Roosen, J., Lusk, J. L., \& Fox, J. A. (2003). Consumer demand for and attitudes toward alternative beef labeling strategies in France, Germany, and the UK. Agribusiness, 19(1), 77-90. http://doi.org/10.1002/agr.10041

Rotter, J. B. (1967). A new scale for the measurement of interpersonal trust 1. Journal of Personality, 35(4), 651-665.

Salazar, M. S. (2015). The dilemma of combining positive and negative items in scales. Psicothema, 27(2), 192-199.

Schlenker, W., \& Villas-Boas, S. B. (2009). Consumer and market responses to mad cow disease. American Journal of Agricultural Economics, 91(4), 1140-1152.

Siegrist, M., Earle, T. C., \& Gutscher, H. (2003). Test of a trust and confidence model in the applied context of electromagnetic field (EMF) risks. Risk Analysis: An International Journal, 23(4), 705-716. JOUR.

Spence, M., Stancu, V., Dean, M., Livingstone, M. B. E., Gibney, E. R., \& Lähteenmäki, L. (2016). Are food-related perceptions associated with meal portion size decisions? A cross-sectional study. Appetite, 103, 377-385.

Stefani, G., Cavicchi, A., Romano, D., \& Lobb, A. E. (2008). Determinants of intention to purchase chicken in Italy: the role of consumer risk perception and trust in different information sources. Agribusiness, 24(4), 523-537. http://doi.org/10.1002/agr.20177

Tonkin, E., Wilson, A. M., Coveney, J., Meyer, S. B., Henderson, J., McCullum, D., ... Ward, P. R. (2019). Consumers respond to a model for (re)building consumer trust in the food system. Food Control, 101, 112-120. http://doi.org/10.1016/J.FOODCONT.2019.02.012

Wilson, A. M., Withall, E., Coveney, J., Meyer, S. B., Henderson, J., McCullum, D., 

... Ward, P. R. (2016). A model for (re) building consumer trust in the food system. Health Promotion International, 32(6), 988-1000.

Worthington, R. L., \& Whittaker, T. A. (2006). Scale Development Research: A Content Analysis and Recommendations for Best Practices. The Counseling Psychologist, 34(6), 806-838. http://doi.org/10.1177/0011000006288127

Wu, L., Wang, H., Zhu, D., Hu, W., \& Wang, S. (2016). Chinese consumers' willingness to pay for pork traceability information-The case of Wuxi. Agricultural Economics, 47(1), 71-79.

Yamagishi, T., \& Yamagishi, M. (1994). Trust and commitment in the United States and Japan. Motivation and Emotion, 18(2), 129-166. JOUR. http://doi.org/10.1007/BF02249397

Yong, A. G., \& Pearce, S. (2013). A beginner's guide to factor analysis: Focusing on exploratory factor analysis. Tutorials in Quantitative Methods for Psychology, 9(2), 79-94.

Zachmann, K., \& Østby, P. (2011). Food, technology, and trust: an introduction. History and Technology, 27(1), 1-10. http://doi.org/10.1080/07341512.2011.548970

Zhang, X., Noor, R., \& Savalei, V. (2016). Examining the Effect of Reverse Worded Items on the Factor Structure of the Need for Cognition Scale. PLOS ONE, 11(6), e0157795. http://doi.org/10.1371/journal.pone.0157795

Zhang, Y., Jing, L., Bai, Q., Shao, W., Feng, Y., Yin, S., \& Zhang, M. (2018). Application of an integrated framework to examine Chinese consumers' purchase intention toward genetically modified food. Food Quality and Preference, 65, 118-128. JOUR. 


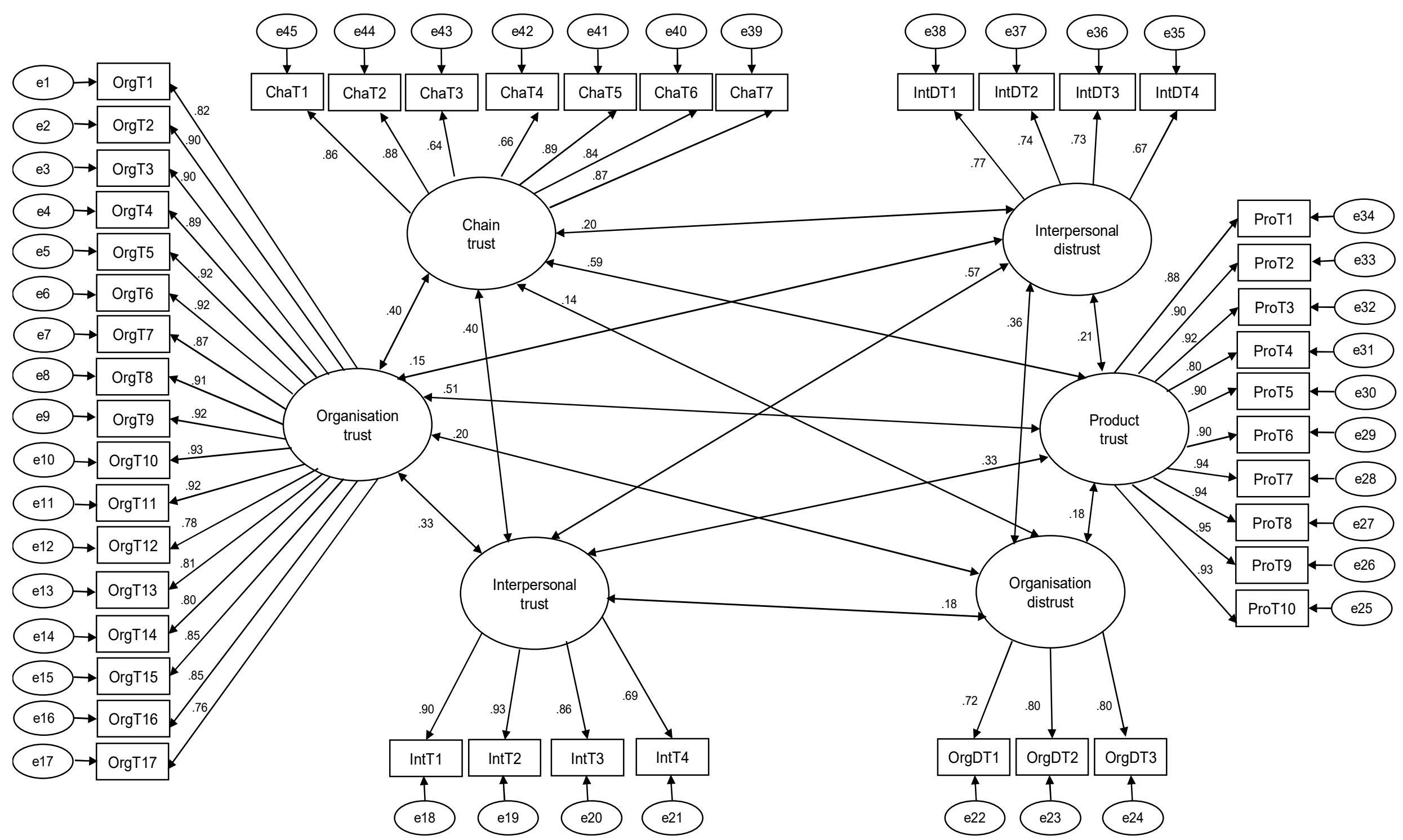

Figure 1: Final measurement model for consumer trust toolkit with standardised factor loadings and correlations 
861 Table 1: Characteristics of participants in study 1 conducted in the UK

\begin{tabular}{lc}
\hline Characteristic & $\%$ \\
\hline Gender & $100 \%$ \\
Male & $49 \%$ \\
Female & $51 \%$ \\
Age & \\
$18-24$ & $13 \%$ \\
$25-34$ & $17 \%$ \\
$35-44$ & $18 \%$ \\
$45-54$ & $18 \%$ \\
$55-64$ & $15 \%$ \\
$65+$ & $20 \%$ \\
Highest level of completed education & \\
Primary school only or incomplete secondary education & $4 \%$ \\
Completed secondary education (GCSE) & $19 \%$ \\
A-Level or vocational qualification & $37 \%$ \\
Undergraduate degree & $28 \%$ \\
Postgraduate degree or doctorate & $11 \%$ \\
Prefer not to answer & $1 \%$ \\
Marital status & \\
Married or living with partner & $65 \%$ \\
Never married & $25 \%$ \\
Separated/widowed/divorced & $10 \%$ \\
Prefer not to answer & $1 \%$ \\
\hline
\end{tabular}


Table 2: Characteristics of participants for each country in study 2

\begin{tabular}{|c|c|c|c|c|c|}
\hline Characteristic/country & UK & Germany & Greece & Finland & Total $n(\%)$ \\
\hline & $100 \%$ & $100 \%$ & $100 \%$ & $100 \%$ & $100 \%$ \\
\hline \multicolumn{6}{|l|}{ Gender } \\
\hline Male & $49 \%$ & $46 \%$ & $46 \%$ & $47 \%$ & $49 \%$ \\
\hline Female & $50 \%$ & $54 \%$ & $54 \%$ & $53 \%$ & $51 \%$ \\
\hline Other & $0 \%$ & $0 \%$ & $0 \%$ & $0 \%$ & $0 \%$ \\
\hline \multicolumn{6}{|l|}{ Age } \\
\hline $18-24$ & $12 \%$ & $11 \%$ & $12 \%$ & $13 \%$ & $12 \%$ \\
\hline $25-34$ & $16 \%$ & $15 \%$ & $22 \%$ & $15 \%$ & $17 \%$ \\
\hline $35-44$ & $14 \%$ & $16 \%$ & $21 \%$ & $18 \%$ & $17 \%$ \\
\hline $45-54$ & $18 \%$ & $18 \%$ & $18 \%$ & $15 \%$ & $17 \%$ \\
\hline $55-64$ & $15 \%$ & $14 \%$ & $16 \%$ & $10 \%$ & $14 \%$ \\
\hline $65+$ & $25 \%$ & $27 \%$ & $12 \%$ & $28 \%$ & $23 \%$ \\
\hline \multicolumn{6}{|l|}{ Highest level of completed education } \\
\hline $\begin{array}{l}\text { Primary school only or incomplete } \\
\text { secondary education }\end{array}$ & $6 \%$ & $6 \%$ & $1 \%$ & $11 \%$ & $6 \%$ \\
\hline $\begin{array}{l}\text { Completed secondary education } \\
\text { (GCSE) }\end{array}$ & $16 \%$ & $17 \%$ & $18 \%$ & $41 \%$ & $23 \%$ \\
\hline A-Level or vocational qualification & $39 \%$ & $55 \%$ & $20 \%$ & $21 \%$ & $34 \%$ \\
\hline Undergraduate degree & $25 \%$ & $6 \%$ & $29 \%$ & $11 \%$ & $20 \%$ \\
\hline Postgraduate degree or doctorate & $14 \%$ & $16 \%$ & $22 \%$ & $12 \%$ & $16 \%$ \\
\hline Prefer not to answer & $0 \%$ & $0 \%$ & $1 \%$ & $4 \%$ & $1 \%$ \\
\hline \multicolumn{6}{|l|}{ Marital status } \\
\hline Married or living with partner & $58 \%$ & $60 \%$ & $62 \%$ & $50 \%$ & $57 \%$ \\
\hline Never married & $25 \%$ & $22 \%$ & $25 \%$ & $30 \%$ & $26 \%$ \\
\hline Separated/widowed/divorced & $16 \%$ & $17 \%$ & $11 \%$ & $7 \%$ & $15 \%$ \\
\hline Prefer not to answer & $1 \%$ & $1 \%$ & $2 \%$ & $2 \%$ & $2 \%$ \\
\hline
\end{tabular}

$867{ }^{*}$ Percentages may add to more than $100 \%$ due to rounding

868

869 
870 Table 3: Fit statistics for each CFA model

\begin{tabular}{cccccc}
\hline & $\boldsymbol{X}^{\mathbf{2}}(\boldsymbol{p}), \boldsymbol{X}^{\mathbf{2}} / \mathbf{d f}$ & RMSEA & $\mathbf{C F I}$ & $\mathbf{N F I}$ & TLI \\
\hline Model 1 & $6371.67(p<0.001), 6.9$ & 0.08 & 0.90 & 0.88 & 0.89 \\
Model 2 & $6423.73(p<0.001), 6.9$ & 0.08 & 0.90 & 0.88 & 0.89 \\
Model 3 & $4733.20(p<0.001), 5.8$ & 0.07 & 0.93 & 0.91 & 0.91 \\
\hline$X^{2}$, chi-square; RMSEA, Root Mean Square Error of Approximation; CFI,
\end{tabular}

871 Comparative Fit Index; NFI, Normed-Fit Index; TLI, Tucker-Lewis Index 


\begin{tabular}{|c|c|c|c|c|c|c|c|}
\hline \multirow[t]{2}{*}{ Label } & \multirow[t]{2}{*}{ Item } & \multicolumn{3}{|c|}{ Organisation Product Interpersonal } & \multirow{2}{*}{$\begin{array}{c}\text { Chain } \\
\text { trust }\end{array}$} & \multicolumn{2}{|c|}{ Organisation Interpersonal } \\
\hline & & trust & trust & trust & & distrust & distrust \\
\hline OrgT1 & You can count on EFSA ${ }^{1}$ & 0.82 & - & - & - & - & - \\
\hline OrgT2 & I trust EFSA ${ }^{1}$ & 0.90 & - & - & - & - & - \\
\hline OrgT3 & Consumers can always rely on EFSA ${ }^{1}$ & 0.90 & - & - & - & - & - \\
\hline OrgT4 & EFSA keep their promises ${ }^{1}$ & 0.89 & - & - & - & - & - \\
\hline OrgT5 & I believe in EFSA ${ }^{2}$ & 0.92 & - & - & - & - & - \\
\hline OrgT6 & I have confidence in EFSA ${ }^{2}$ & 0.92 & - & - & - & - & - \\
\hline OrgT7 & EFSA make me feel safe ${ }^{3}$ & 0.87 & - & - & - & - & - \\
\hline OrgT8 & EFSA is sincere with consumers ${ }^{3}$ & 0.91 & - & - & - & - & - \\
\hline OrgT9 & EFSA is honest with consumers ${ }^{3}$ & 0.92 & - & - & - & - & - \\
\hline OrgT10 & EFSA is dependable ${ }^{4}$ & 0.93 & - & - & - & - & - \\
\hline OrgT11 & I trust EFSA to provide accurate information ${ }^{5}$ & 0.92 & - & - & - & - & - \\
\hline OrgT12 & EFSA has a good understanding of all the issues relevant ${ }^{6}$ & 0.78 & - & - & - & - & - \\
\hline OrgT13 & EFSA take their responsibility to society seriously ${ }^{6}$ & 0.81 & - & - & - & - & - \\
\hline OrgT14 & EFSA are good at looking at the evidence and judging what to do ${ }^{6}$ & 0.80 & - & - & - & - & - \\
\hline OrgT15 & EFSA has practices that favour the consumer's best interests ${ }^{4}$ & 0.85 & - & - & - & - & - \\
\hline OrgT16 & $\begin{array}{l}\text { EFSA considers the consumer's welfare when making important } \\
\text { decisions }{ }^{4}\end{array}$ & 0.85 & - & - & - & - & - \\
\hline OrgT17 & $\begin{array}{l}\text { EFSA considers how future decisions and actions will affect the } \\
\text { consumer }{ }^{4}\end{array}$ & 0.76 & - & - & - & - & - \\
\hline ProT1 & I trust that EU beef burgers are high quality ${ }^{7}$ & - & 0.88 & - & - & - & - \\
\hline ProT2 & EU beef burgers are reliable ${ }^{7}$ & - & 0.90 & - & - & - & - \\
\hline ProT3 & I trust that EU beef burgers are safe ${ }^{8}$ & - & 0.92 & - & - & - & - \\
\hline ProT4 & I trust that EU beef burgers are fully traceable back to their origin ${ }^{9}$ & - & 0.80 & - & - & - & - \\
\hline ProT5 & I trust that EU beef burgers are authentic ${ }^{9}$ & - & 0.90 & - & - & - & - \\
\hline ProT6 & I trust that EU beef burgers are accurately labelled & - & 0.90 & - & - & - & - \\
\hline ProT7 & EU beef burgers are trustworthy & - & 0.94 & - & - & - & - \\
\hline ProT8 & EU beef burgers are honest & - & 0.94 & - & - & - & - \\
\hline ProT9 & EU beef burgers are truthful & - & 0.95 & - & - & - & - \\
\hline ProT10 & EU beef burgers have integrity & - & 0.93 & - & - & - & - \\
\hline
\end{tabular}




\begin{tabular}{|c|c|c|c|c|c|c|c|}
\hline \multirow[t]{2}{*}{ Label } & \multirow[t]{2}{*}{ Item } & \multicolumn{3}{|c|}{ Organisation Product Interpersonal } & \multirow{2}{*}{$\begin{array}{l}\text { Chain } \\
\text { trust }\end{array}$} & \multicolumn{2}{|c|}{ Organisation Interpersonal } \\
\hline & & trust & trust & trust & & distrust & distrust \\
\hline IntT1 & Most people are basically honest ${ }^{10}$ & - & - & 0.90 & - & - & - \\
\hline IntT2 & Most people are trustworthy ${ }^{10}$ & - & - & 0.93 & - & - & - \\
\hline IntT3 & Most people are basically good and kind ${ }^{10}$ & - & - & 0.86 & - & - & - \\
\hline IntT4 & Most people are trustful of others ${ }^{10}$ & - & - & 0.69 & - & - & - \\
\hline ChaT1 & Food manufacturers take good care of the safety of our food ${ }^{11}$ & - & - & - & 0.86 & - & - \\
\hline ChaT2 & Food manufacturers give special attention to the safety of food ${ }^{11}$ & - & - & - & 0.88 & - & - \\
\hline ChaT3 & $\begin{array}{l}\text { Food manufacturers have the competence to control the safety of } \\
\text { food }^{11}\end{array}$ & - & - & - & 0.64 & - & - \\
\hline ChaT4 & $\begin{array}{l}\text { Food manufacturers have sufficient knowledge to guarantee the safety } \\
\text { of food products }{ }^{11}\end{array}$ & - & - & - & 0.66 & - & - \\
\hline ChaT5 & Food manufacturers are honest about the safety of food ${ }^{11}$ & - & - & - & 0.89 & - & - \\
\hline ChaT6 & Food manufacturers are sufficiently open regarding the safety of food ${ }^{11}$ & - & - & - & 0.84 & - & - \\
\hline ChaT7 & $\begin{array}{l}\text { Food manufacturers can be trusted to protect the consumer from } \\
\text { unsafe food }{ }^{12}\end{array}$ & - & - & - & 0.87 & - & - \\
\hline OrgDT1 & Information from EFSA is distorted ${ }^{13}$ & - & - & - & - & 0.72 & - \\
\hline OrgDT2 & Information from EFSA has been proven wrong in the past ${ }^{13}$ & - & - & - & - & 0.80 & - \\
\hline OrgDT3 & $\begin{array}{l}\text { EFSA provides accurate information only to protect themselves and } \\
\text { their own interests }{ }^{13}\end{array}$ & - & - & - & - & 0.80 & - \\
\hline IntDT1 & If given a chance, most people would try to take advantage of you ${ }^{14}$ & - & - & - & - & - & 0.77 \\
\hline IntDT2 & Most people are too busy looking out for themselves to be helpful ${ }^{14}$ & - & - & - & - & - & 0.74 \\
\hline IntDT3 & You can't trust strangers anymore ${ }^{14}$ & - & - & - & - & - & 0.73 \\
\hline IntDT4 & I never rely on other people ${ }^{14}$ & - & - & - & - & - & 0.67 \\
\hline 874 & ${ }^{1}$ Item adapted from Perrini et al. (2010) & & & & & & \\
\hline 875 & ${ }^{2}$ Item adapted from Nuttavuthisit \& Thøgersen (2017) & & & & & & \\
\hline 876 & ${ }^{3}$ Item adapted from Gurviez \& Korchia (2003) & & & & & & \\
\hline 877 & ${ }^{4}$ Item adapted from Brudvig (2015) & & & & & & \\
\hline 878 & ${ }^{5}$ Item adapted from Zhang et al. (2018) & & & & & & \\
\hline 879 & ${ }^{6}$ Item adapted from Allum (2007) & & & & & & \\
\hline 880 & ${ }^{7}$ Item adapted from Lassoued et al. (2015) & & & & & & \\
\hline 881 & ${ }^{8}$ Item adapted from Ariyawardana, Ganegodage, \& Mortlock (2017) & & & & & & \\
\hline
\end{tabular}


9 Item adapted from Spence et al. (2016)

$883{ }^{10}$ Item from Yamagishi \& Yamagishi (1994)

$884{ }^{11}$ Item adapted from de Jonge, van Trijp, van der Lans, Renes, \& Frewer (2008)

$885{ }^{12}$ Item adapted from Kendall et al. (2018)

$886{ }^{13}$ Item adapted from Frewer, Scholderer, \& Bredahl (2003)

$887{ }^{14}$ Item from Siegrist, Earle \& Gutscher (2003) 
888 Table 5: Associations between existing scales and consumer toolkit scales for

889 convergent validity

\begin{tabular}{llc}
\hline Consumer toolkit scale & \multicolumn{1}{c}{ Previously associated or existing scale } & $\mathbf{r}_{\mathbf{s}}$ \\
\hline Interpersonal trust & Commonly used general trust item (1 item) & $0.64^{* *}$ \\
Interpersonal trust & Life satisfaction & $0.31^{* *}$ \\
Organisation trust & Number of sources of information wanted if risk to & $0.13^{* *}$ \\
& food safety & $-0.40^{*}$ \\
Organisation trust & Corporate distrust scale & $0.16^{* *}$ \\
Chain trust & Frequency of buying & $-0.11^{* *}$ \\
Chain trust & Food quality interest & $0.41^{* *}$ \\
Product trust & Frequency of buying & $-0.17^{* *}$ \\
Product trust & Food quality interest & \\
\hline
\end{tabular}

890

${ }^{* *} p<0.01$

891

892

893 
894 Table 6: Correlations, square root of Average Variance Extracted (AVE) and Maximum 895 Shared Variance (MSV) for each of the scales in the toolkit

\begin{tabular}{lccccccc}
\hline \multicolumn{1}{c}{ Scale } & IT & ID & OT & OD & CT & PT & MSV \\
\hline Interpersonal Trust (IT) & $\mathbf{0 . 8 5}$ & - & - & - & - & - & 0.32 \\
Interpersonal Distrust (ID) & 0.57 & $\mathbf{0 . 7 3}$ & - & - & - & - & 0.32 \\
Organisation Trust (OT) & 0.33 & 0.15 & $\mathbf{0 . 8 7}$ & - & - & - & 0.26 \\
Organisation Distrust (OD) & 0.18 & 0.36 & 0.20 & $\mathbf{0 . 7 7}$ & - & - & 0.13 \\
Chain Trust (CT) & 0.40 & 0.20 & 0.46 & 0.14 & $\mathbf{0 . 8 1}$ & - & 0.35 \\
Product Trust (PT) & 0.33 & 0.21 & 0.51 & 0.18 & 0.59 & $\mathbf{0 . 9 1}$ & 0.35 \\
\hline
\end{tabular}

896 Square root of AVE shown in bold on diagonal

897 Note: The trust and distrust scales are positively correlated as the distrust items have been

898 reverse scored

899

900

901 
902 Table 7: Characteristics of participants for each country in study 3

\begin{tabular}{|c|c|c|c|c|c|}
\hline Characteristic/country & UK & Germany & Greece & Finland & Total $n(\%)$ \\
\hline & $100 \%$ & $100 \%$ & $100 \%$ & $100 \%$ & $100 \%$ \\
\hline \multicolumn{6}{|l|}{ Gender } \\
\hline Male & $56 \%$ & $43 \%$ & $46 \%$ & $45 \%$ & $47 \%$ \\
\hline Female & $44 \%$ & $57 \%$ & $54 \%$ & $55 \%$ & $53 \%$ \\
\hline \multicolumn{6}{|l|}{ Age } \\
\hline $18-24$ & $2 \%$ & $5 \%$ & $11 \%$ & $7 \%$ & $7 \%$ \\
\hline $25-34$ & $10 \%$ & $10 \%$ & $26 \%$ & $8 \%$ & $14 \%$ \\
\hline $35-44$ & $17 \%$ & $19 \%$ & $16 \%$ & $23 \%$ & $19 \%$ \\
\hline $45-54$ & $20 \%$ & $19 \%$ & $13 \%$ & $18 \%$ & $17 \%$ \\
\hline $55-64$ & $14 \%$ & $10 \%$ & $20 \%$ & $7 \%$ & $13 \%$ \\
\hline $65+$ & $37 \%$ & $36 \%$ & $14 \%$ & $37 \%$ & $30 \%$ \\
\hline \multicolumn{6}{|l|}{ Highest level of completed education } \\
\hline $\begin{array}{l}\text { Primary school only or incomplete } \\
\text { secondary education }\end{array}$ & $9 \%$ & $7 \%$ & $0 \%$ & $10 \%$ & $6 \%$ \\
\hline $\begin{array}{l}\text { Completed secondary education } \\
\text { (GCSE) }\end{array}$ & $20 \%$ & $19 \%$ & $21 \%$ & $42 \%$ & $26 \%$ \\
\hline A-Level or vocational qualification & $37 \%$ & $59 \%$ & $19 \%$ & $20 \%$ & $33 \%$ \\
\hline Undergraduate degree & $20 \%$ & $5 \%$ & $30 \%$ & $13 \%$ & $18 \%$ \\
\hline Postgraduate degree or doctorate & $14 \%$ & $10 \%$ & $29 \%$ & $12 \%$ & $17 \%$ \\
\hline Prefer not to answer & $0 \%$ & $0 \%$ & $1 \%$ & $3 \%$ & $1 \%$ \\
\hline \multicolumn{6}{|l|}{ Marital status } \\
\hline Married or living with partner & $58 \%$ & $64 \%$ & $61 \%$ & $47 \%$ & $58 \%$ \\
\hline Never married & $19 \%$ & $17 \%$ & $26 \%$ & $32 \%$ & $24 \%$ \\
\hline Separated/widowed/divorced & $24 \%$ & $19 \%$ & $11 \%$ & $20 \%$ & $18 \%$ \\
\hline Prefer not to answer & $0 \%$ & $0 \%$ & $1 \%$ & $2 \%$ & $1 \%$ \\
\hline
\end{tabular}

$903{ }^{*}$ Percentages may add to more than $100 \%$ due to rounding

904

905

906 
907 Table 8: Composite reliability (CR) and Intra-class correlation coefficient (ICC) values

908 for each of the scales in the toolkit

\begin{tabular}{lcc}
\hline Consumer toolkit scale & Composite reliability & Intra-class correlation \\
\hline Interpersonal trust & 0.91 & 0.72 \\
Interpersonal distrust & 0.82 & 0.79 \\
Organisation trust & 0.98 & 0.68 \\
Organisation distrust & 0.82 & 0.53 \\
Chain trust & 0.93 & 0.72 \\
Product trust & 0.98 & 0.69 \\
\hline
\end{tabular}

909

910 